\title{
Assessment of salinity tolerance in polycross progenies of tall fescue [Lolium arundinaceum (Schreb) S. J. Darbysh.)]
}

\author{
Fatemeh Amini*, Dariush Sadeghi
}

\author{
Department of Agronomy and Plant Breeding Sciences, University of Tehran, College of Aburaihan \\ P.O.Box:3391653755 Tehran, Iran
}

\section{*Corresponding author: aminif@ut.ac.ir (Dr Fatemeh Amini)}

\begin{abstract}
The effect of salinity on germination factors was evaluated for twenty five genotypes as the parents and first generation synthetic progenies (Syn1) of tall fescue. To produce polycross seeds, four groups of six parental plants with contrasting levels of diversity based on phenotypic traits and contrasting levels of AFLP molecular marker diversity constructed. An experimental factorial, in a randomized complete block design was conducted under five salinity levels $(0,50,100,150,200 \mathrm{mM} \mathrm{NaCl})$. In each experiment 10 $\mathrm{ml}$ from salt solution was added to each Petri dish. Seeds were allowed to germinate at $25 \pm 1^{\circ} \mathrm{C}$ for 14 days. Daily, final germination and emergence percentage, as well as germination and seedling emergence rate, and seedling fresh and dry weight were measured in the study under controlled and stress conditions in parental genotypes and also first generation progenies. The results showed that the differences between parents of populations were not significant for the evaluated traits but the effect of population in progenies were significant for all of the evaluated traits. It seems that the polycrosses of the parental genotypes gathered the positive genes in progenies and caused the significant increases in the evaluated traits such as germination percent, germination rate, fresh weight of leaf and radical length. HMD and LMD populations had the highest means for most of the evaluated traits such as germination percentage and germination rate in all stress and non-stress conditions. The parents of these population selected based on molecular markers diversities. The correlation between similarity matrix of parents based on molecular markers and the similarity matrix of first generation of progenies based on morphological traits was significant $(\mathrm{r}=0.35)$. The highest broad sense heritability was observed for fresh weight of radical in parents and progenies (70\% and $80 \%$ ), while the lowest was observed for radical length in both parents and progenies (13\% and 15\%). Our results demonstrate that molecular markers can be reliable tools to efficiently selecting parental genotypes and improving tall fescue breeding programs.
\end{abstract}

Keywords: Germination, Salinity, synthetic variety, tall fescue.

Abbreviations: DWL_dry weight of leaf, DWR_dry weight of radical, FWL_fresh weight of leaf, FWR_fresh weight of radical, GP_Germination percentage, GR_germination rate, LL_leaf length, RL_radical length.

\section{Introduction}

The major abiotic stresses such as drought, high salinity, cold, and heat are responsible for more than $70 \%$ yield reduction (Shanker and Venkateswarlu, 2011; Mantri et al., 2012). Global estimates indicated that at least 1.5 billion hectares of land were affected by salinity (Yensen, 1995). It is reported that salinity can reduce crop yield in $20 \%$ of all cultivated land and almost half of irrigated land (Munns, 2006; Jones, 2007). Salinity stress disrupts homeostasis in plant water potential and ion distribution at both cellular and whole plant levels. It can cause damage to biological molecules, plant growth arrest and finally leads to plant death (Munns and Tester, 2008). The initial and primary effect of salinity is due to its osmotic effects and specific ion toxicity. Rising of osmotic pressure can decrease water movement into the seeds during imbibitions that it leads to reduced germination rate and the final seed germination (DeRoseWilson and Gaut, 2011). Seed germination and early seedling growth are important phases for seed establishment that can determine the successfully of crop production. The available literature revealed the effects of salinity on the seed germination of various crops like Oryza sativa (Xu et al.,
2011), Triticum aestivum (Akbarimoghaddam et al., 2011), Zea mays (Khodarahmpour et al., 2012). Various germination experiments have been used to evaluate relative salinity tolerance in turf grasses during seed germination. Marcum (1994) and Wang and Zhang (2010) germinated bentgrass (Agrostis spp.) seeds on different salinity levels. Dai et al. (2009) also compared salinity tolerance of greens-type $P$. annua. Germination rate and seedling growth (blade length and tissue weight) of perennial ryegrass, kentucky bluegrass, and tall fescue cultivars under saline conditions were evaluated in hydroponic systems (Horst and Beadle, 1984; Horst and Dunning, 1989; Horst and Taylor, 1983). Similar trends were observed that seed germination and seedling growth are reduced as saline stress severity increases. Increasing the salt tolerance of conventional crop plants is the most common solution. The salt-resistant genotypes can successfully cope with osmotic and ionic stresses caused by the excess of $\mathrm{NaCl}$; they can effectively reduce the oxidative damage and are able to detoxify the harmful metabolites (Tari, et al., 2010). Measurement of morphological index of grown plants in those conditions can be a good indicator to 
determine tolerable plant to stress (Shalhevet, 1993). $\mathrm{NaCl}$ have been used to stimulate osmotic stress effects in vitro for plants to maintain uniform water potential throughout the experimental period (Misra and Dwivedi, 2004). Plants with higher percentage of germination under stress condition have more chance to go green (Ashraf et al., 1992). Tall fescue (Lolium arundinaceum (Schreb) S. J. Darbysh.) is a popular cool-season grass species. This plant is an out crossing allohexaploid $(2 \mathrm{n}=6 \mathrm{x}=42)$ grass species and known to have a bunching growth habit, but botanically, it is also considered weakly rhizomatous. Tall fescue widely used for forage and turf worldwide. It is native to much of Europe, North Africa, parts of the Middle East, central Asia and Siberia (Xu et al., 1994), and it also has been introduced to North America, Japan, Australia, and New Zealand. Tall fescue has been popular in areas where it has been introduced. Since tall fescue is an open pollinated species with a high level of selfincompatibility (Xu et al., 1994), cultivars are typically produced through random mating of selected parental plants called synthetic varieties, (Barker and Kalton, 1989). Synthetic varieties need a firm level of phenotypic homogeneity to pass variety trials and also a high level of heterozygosity to maximize adaptability and agronomic performance. Therefore, finding the optimal level of diversity in synthetic cultivars is very important (Amini et al., 2013). Molecular markers offer powerful tools for the analysis of genetic diversity independent of the environment. Molecular marker assisted parental selection may allow optimization of parental combinations in order to maximize heterosis and to minimize inbreeding. In perennial ryegrass (Kölliker et al., 2005), tall fescue (Amini et al., 2013) selection of genetically diverse parents based on molecular markers was shown to lead to better agronomic performance in first and second generation progenies. Identifying varieties with salinity tolerance may offer opportunities for future breeding efforts and provide growers with increased flexibility for cultivation area. Therefore, the aims of this study were screening the first generation of synthetic populations for salinity tolerance to compare the different methods of parental selection.

\section{Results and Discussion}

\section{Analysis of variance and mean value}

Analysis of variance showed that the effect of population and population $\times$ salinity were not significant for all the evaluated characters in parental populations. The effect of salinity was significant for all the characters with the exception of DWL and DWR (Table 1). In progenies populations the effects of population and population $\times$ salinity were significant for all the evaluated traits with the exception of DWR and DWL. Salt stress decreased the FWL, FWR, DWL and DWR. This reduction was relatively depended on shoot or root lengths. Decrease in the traits due to the effect of increasing salt concentration (Fig2-5) may be resulted from decreasing osmosis potential of solution, increasing toxic ions and changing in the remobilization balance of seed reservoirs. Under control condition the highest GP means were recorded for HMD and LMD those have long term growing period regarding its phenological features (Amini et al., 2010). The maximum GR in control condition was recorded for HMD, LMD, LPD, HPD, respectively. The difference between LPD and HPD was not significant (Fig 3). In control condition the highest FWL belonged to LMD and the lowest means observed in HPD (Fig 4). HMD population had the highest means for GP and GR in all stress and non-stress conditions (Fig 2,3). The results showed that the differences between parents of populations were not significant for the evaluated traits (Table 1) but the effect of population in progenies were significant for all of the evaluated traits. It seems that the polycrosses of the parental genotypes gathered the positive genes in progenies and caused the significant increases in the evaluated traits such as germination percent, germination rate, fresh weight of leaf and radical length. HMD and LMD populations had the highest means for most of the evaluated traits. The parents of these population selected based on molecular markers diversities. The correlation between similarity matrix of parents based on molecular markers and the similarity matrix of first generation of progenies based on morphological traits was significant $(\mathrm{r}=0.35)$. It seems that there are relationship between the molecular markers used for selecting the parents and the salinity resistant genes in the progenies. However, in $150 \mathrm{~mm}$ and $200 \mathrm{~mm}$ stress conditions the differences between four populations were not significant for FWL and RL (Fig 4, 5). The results demonstrated that, response of RL to salt stress was more severe than LL (Table 1). The reduction in root and shoot development may be due to toxic effects of the higher level of $\mathrm{NaCl}$ concentration as well as unbalanced nutrient uptake by the seedlings. The high stress conditions prevent the genetic potential of the genotypes. Zhang and Wang (2012) indicated that salinity adversely affects plant growth and development, resulting in reduced aesthetical and playable functions of turf grass. Zabihi-e-Mahmoodabad et al. (2011) reported that the shoot and root fresh and dry weights decreased with increasing salinity and many other studies also reported this trait as the main indicator of salinity tolerance. Moreover, Hussein et al. (2007) and Carpici et al. (2009) reported that a negative relationship was detected between the vegetative growth parameters and increasing salinity.

\section{Phenotypic variance $\left(\sigma^{2} p\right)$, genetic variance $\left(\sigma^{2} g\right)$ and Coefficient of phenotypic variation $(\mathrm{CVp})$ and coefficient of genetic variation $(\mathrm{CVg})$}

Small differences between phenotypic and genetic variance for most of the traits indicated that the largest part of the observed variation was due to genetic factors (Table 1).

The phenotypic coefficient of variation $(\mathrm{CVp})$ and the genotypic coefficients of variation $(\mathrm{CVg})$ were positive for all the traits. High CVp and CVg were observed in DWR (0.36 and 0.18) in parental genotypes and (1.97 and 1.18) in progenies indicating the presence of high variability in the characters and the potentials for their improvement through selection. Low phenotypic $(\mathrm{CVp})$ and genotypic $(\mathrm{CVg})$ coefficient of variations were observed in RL (0.05 and 0.02), FWL (0.14 and 0.05), and DWL (0.15 and 0.07) for parents and in RL (0.05 and 0.02), FWL (0.13 and 0.07), and LL $(0.26$ and 0.18$)$ in progenies indicated the unstable nature of the traits and are indicative of difficulty for improvement of the traits through selection but using the molecular marker and decrease the effect of environment interaction can help the breeder to improve these traits (Falconer and Mackay 1996). Observation of genetic variability in this study agreed with the results of the others who found significant difference among tall fescue genotypes for germination and emergence traits (Rouhi et al., 2011; Zhou 2006).

\section{Heritability}

Traits with high heritability estimates for parental genotypes were weight of radical (69.76\%) and leaf length (31.57\%) 
Table 1. Population Mean square (PMS), Mean value, phenotypic variance $\left(\sigma_{\mathrm{p}}^{2}\right.$ ), genetic variance $\left(\sigma_{\mathrm{g}}^{2}\right)$, coefficient of phenotypic variation $\left(\mathrm{CV}_{\mathrm{p}}\right)$, coefficient of genetic variation $\left(\mathrm{CV}_{\mathrm{g}}\right)$ and broad-sense heritability $\left(\mathrm{h}_{\mathrm{b}}^{2}\right)$ of phenotypic traits evaluated in four populations over 3 replications for parents (in the top) and first generation progenies (in the bottom).

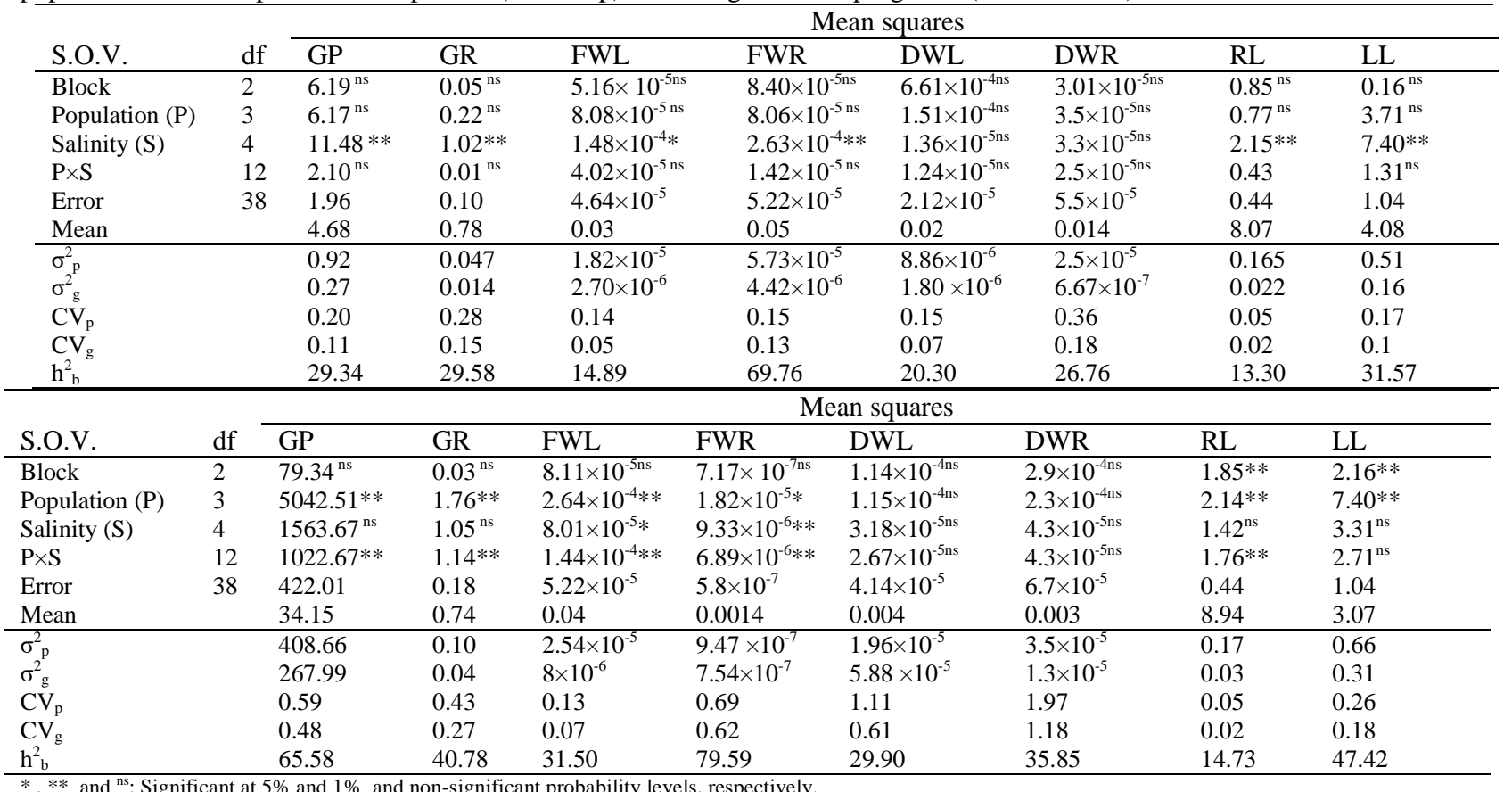

$*, * *$ and ${ }^{\mathrm{ns}}$ : Significant at $5 \%$ and $1 \%$ and non-significant probability levels, respectively.
Germination percentage (GP), germination rate (GR), fresh weight of leaf (FWL), fresh weight of radical (FWR), dry weight of leaf (DWL), dry weight of radical (DWR), radical length (RL), leaf length (LL).

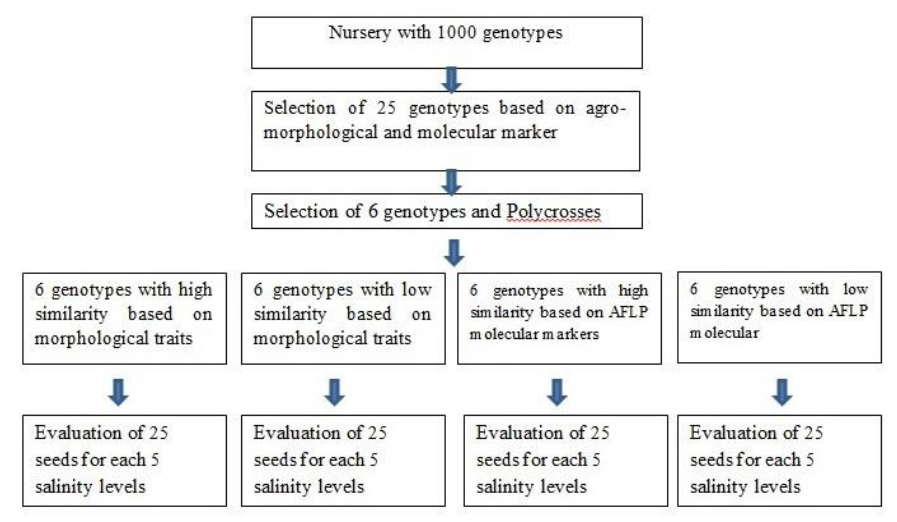

Fig 1. A schematic diagram depicting how synthetic populations were produced.

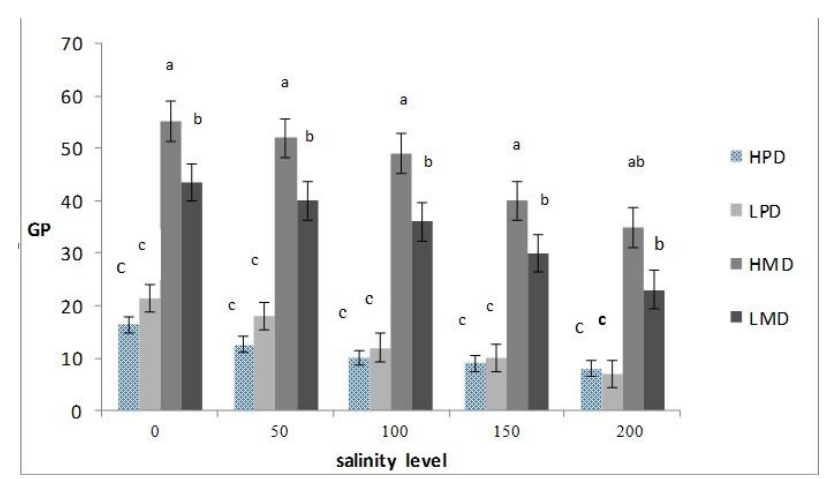

Fig 2. Comparison four synthetic varieties in different salinity levels for GP (germination percentage). The alphabets show the population $\times$ salinity interaction. Means followed by the same letter are not significantly differ according to the Duncan's test at the 0.01 level of significance. HPD (high phenotypic diversity, LPD (low phenotypic diversity), HMD (high molecular genetic), LMD (low molecular genetic), HGCA (high general combining ability). 


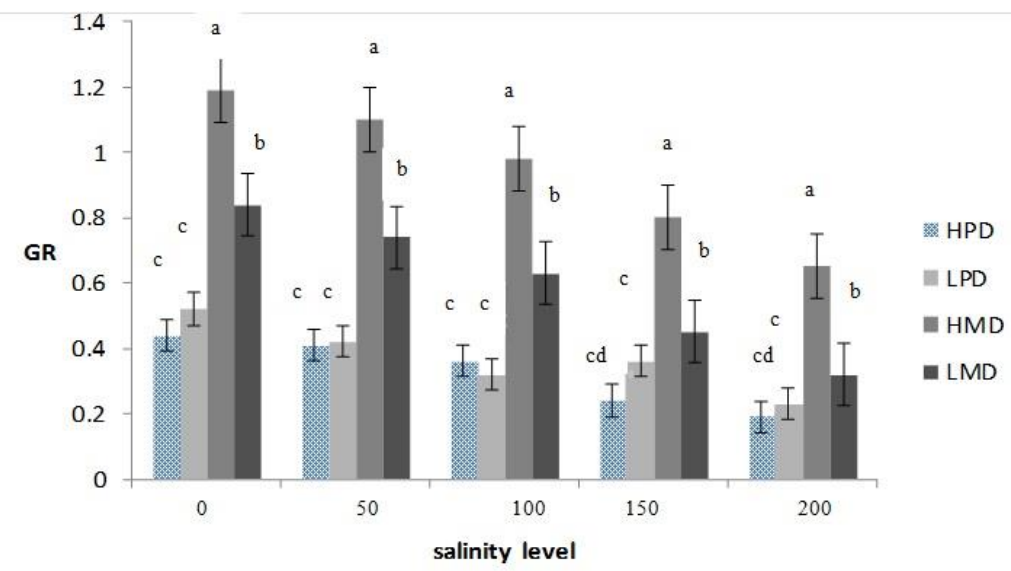

Fig 3. Comparison four synthetic varieties in different salinity levels for GR (Germination Rate). The alphabets show the population $\times$ salinity interaction. Means followed by the same letter are not significantly differ according to the Duncan's test at the 0.01 level of significance. HPD (high phenotypic diversity, LPD (low phenotypic diversity), HMD (high molecular genetic), LMD (low molecular genetic), HGCA (high general combining ability).

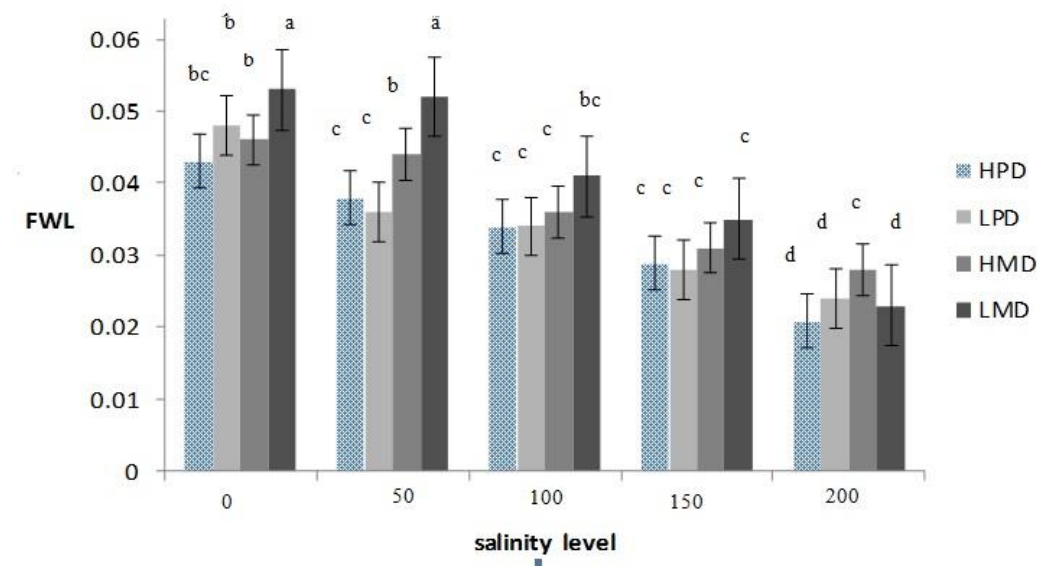

Fig 4. Comparison four synthetic varieties in different salinity levels for FWL (fresh weight of leaf). The alphabets show the population $\times$ salinity interactions. Means followed by the same letter are not significantly differ according to the Duncan's test at the 0.01 level of significance. HPD (high phenotypic diversity, LPD (low phenotypic diversity), HMD (high molecular genetic), LMD (low molecular genetic), HGCA (high general combining ability)

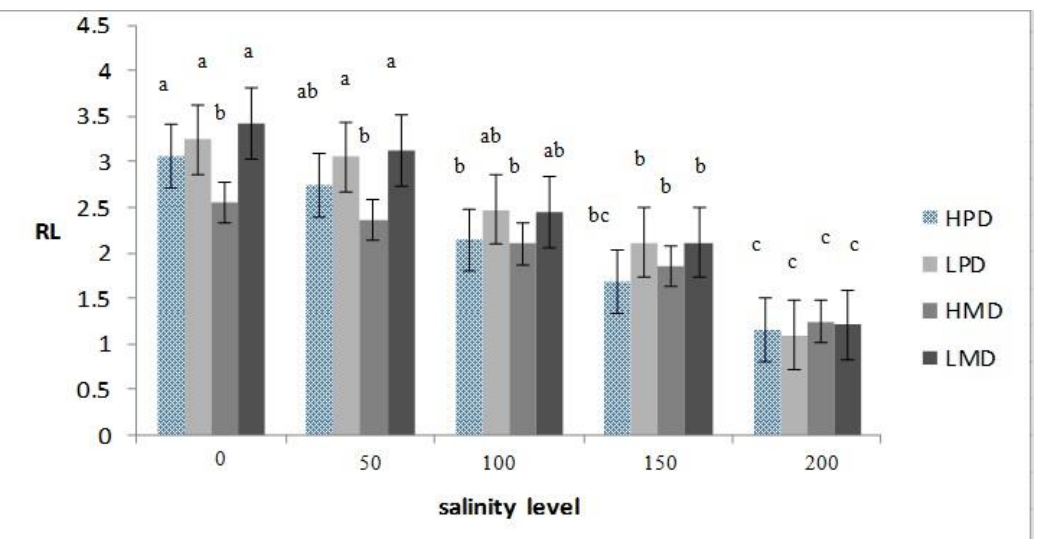

Fig 5. Comparison four synthetic varieties in different salinity levels for RL (Root Length). The alphabets show the population $x$ salinity interactions. Means followed by the same letter are not significantly differ according to the Duncan's test at the 0.01 level of significance. HPD (high phenotypic diversity, LPD (low phenotypic diversity), HMD (high molecular genetic), LMD (low molecular genetic), HGCA (high general combining ability). 
and for first generation progenies were fresh weight of radical $(79.6 \%)$, germination percentage $(65.6 \%)$, leaf length $(47.5 \%)$ and germination rate $(41 \%)$. High heritability indicates the more importance of genetic factors in controlling a trait and possibility of its improvement by appropriate selection program. Genetic variation and high heritability are the main requirements of genetic gain from selection (Falconer and Mackay 1996). The heritability ranging from $15 \%$ to $79.6 \%$ indicated that non genetic components or environment had minor effect on the phenotypic expression of traits with higher heritability such as fresh weight of radical. To improve these traits with low heritability using the molecular marker to decrease the effect of environment is desire. Heritability for salt tolerance has been studies in other crops such as rice (Gregorio and Senadhira 1993), alfalfa (Allen et al., 1985) and forage species (Ashraf et al., 1987) indicating that selection in the germination stage would be effective. By combining conventional breeding techniques with molecular marker information the reliable selection method for salt tolerance in segregating population can be achieved.

\section{Materials and methods}

\section{Plant Material and Experimental Design}

The 25 parental germplasm was selected from a large replicated nursery of tall fescue based on seed yield and resistant to salinity. In order to produce polycrosses progenies 25 parental genotypes clustered in to 4 groups of six parental plants with contrasting levels of diversity based on phenotypic traits and two polycrosses of six parental plants with contrasting levels of molecular marker diversity as determined using AFLP markers (Amini et al. 2016). Seeds of first generation synthetic progenies (Syn1) were harvested on each parental genotype and equal amounts of Syn1 seed from each parent were pooled per polycross nursery. Twenty five seeds of parental genotypes and 25 seeds of first generation synthetic progenies (Syn1) were evaluated for salinity stress in this study (Fig 1). This experiment was conducted in the seed technology lab of College of Aburaihan, University of Tehran, in 2015. The experimental design was 2 factors, arranged in a randomized complete block design with 3 replications. Seeds were subjected to salt germination using osmotic potentials $(0,50,100,150$ and $200 \mathrm{~mm}$ or is equal to $0,-0.22,-0.42,-0.62$ and $-0.82 \mathrm{MPa}$ ) of sodium chloride ( $\mathrm{NaCl}$ ) (Safarnejad et al., 1996). Seeds were kept in sodium hypochlorite $(1.5 \%)$ for one minute and then were washed with distilled water. After disinfecting, seeds were put in disinfected Petri dishes. Twenty-five seeds were placed on double-layered with Whatman No. 1 filter papers placed in $10 \mathrm{~cm}$ diameter plastic dishes. In each experiment $10 \mathrm{ml}$ from salt solution was added to each Petri dish. Seeds were allowed to germinate at $25 \pm 1^{\circ} \mathrm{C}$ for 14 days. The papers were replaced every 2 days to prevent accumulation of salts (Rehman et al., 1996). Petri dishes were hermetically sealed with parafilm to prevent solution evaporation during the experimental. All Petri dishes were kept in dark incubators maintained at room temperature at $25^{\circ} \mathrm{C}$ in the dark. Germination was monitored daily. The germinated seeds were recorded every day for a period of 14 days after sowing. Seeds were considered germinated when the radicle had protruded $2 \mathrm{~mm}$ through the seed coat.

\section{Measurement of traits}

After 14 days, morphological traits such as germination percentage (GP), germination rate (GR) according to the method of Maguire's equation (Pezzani and Montana, 2006), fresh weight of leaf (FWL), fresh weight of radical (FWR), dry weight of leaf (DWL), dry weight of radical (DWR), radical length (RL) as well as leaf length (LL) were studied. Ten seedlings from each petri were taken randomly and studied parameters were measured. Seedling dry weight was determined for after drying the samples in a forced-air dryer at $80^{\circ} \mathrm{C}$ for $48 \mathrm{~h}$ (Bohm, 1979). To calculate the percentage and speed of germination we used following formulas:

Percentage of germination: (T/S) / 100

Germination rate: $\sum\left(\mathrm{N}_{\mathrm{i}} / \mathrm{D}_{\mathrm{i}}\right) / \mathrm{T}$

That $\mathrm{T}$ is number of germinated seed, $\mathrm{S}$ is the number of all seed at first, $\mathrm{N}_{\mathrm{i}}$ is the number of germinated seed in the day of $i$ and $D_{i}$ is the number of days after beginning test (Dhillon, 1995).

\section{Formulas of Genetic Parameters}

Heritability estimates were obtained using variance components as:

Broad sense heritability:

$\mathrm{h}_{\mathrm{b}}{ }^{2}=\sigma_{\mathrm{g}}^{2} / \sigma_{\mathrm{p}}^{2}$

Where $\sigma_{\mathrm{g}}^{2}$ and $\sigma_{\mathrm{p}}^{2}$ are genetic variance and phenotypic variance, respectively.

$\sigma_{p}^{2}=\sigma_{g}^{2}+\sigma_{e / r}^{2}$

$\sigma_{\mathrm{e}}^{2}=$ environmental variance; $\mathrm{r}=$ number of replications

Genotypic coefficient of variation $\left(\mathrm{CV}_{\mathrm{g}}\right)$ and phenotypic coefficient of variation $\left(\mathrm{CV}_{\mathrm{p}}\right)$ were calculated by the:

$\mathrm{CV}_{\mathrm{g}}=\left(\sigma_{\mathrm{g}} / \mu\right) 100$

$\mathrm{CV}_{\mathrm{p}}=\left(\sigma_{\mathrm{p}} / \mu\right) 100$

Where $\sigma_{\mathrm{p}}$ is the standard deviation of the genotypic effect, $\sigma_{\mathrm{g}}$ is the standard deviation of the genotypic effect and $\mu$ is the phenotypic mean.

\section{Statistical analysis}

Data were subjected to Analysis Of Variance (ANOVA), according to Gomez and Gomez (1984). Data given in percentages were subjected to arcsine transformation before statistical analysis. Averages of the main effects and their interactions were compared using the revised Least Significant Difference test (LSD) at 0.05 level of probability. Computations and statistical analysis were done using SAS 9.0 and Excel 2007.

\section{Conclusion}

The present study on the salt tolerance of first generation of synthetic varieties of tall fescue showed a marked variation in their sensitivity to salt tolerance. The increasing $\mathrm{NaCl}$ concentration caused harmful effects on seed germination in the evaluated properties such as, germination percentage, germination rate, root length and fresh weight. However, High molecular diversity (HMD) population had the highest means for GP and GR in all stress and non-stress conditions and Low molecular diversity (LMD) population had the highest means for FWL and RL in control condition and 50 $\mathrm{mm} \mathrm{NaCl}$ concentration. The correlation between similarity matrix of parents based on molecular markers and the similarity matrix of first generation of progeny based on morphological traits was significant $(\mathrm{r}=0.35)$.Our results demonstrate that molecular markers can be reliable tools to efficiently selecting parental genotypes and improving tall fescue breeding programs. 


\section{Acknowledgements}

We are thankful to Dr Mirlohi and Dr. Majidy from Isfahan University of technology who provided the parental genotypes.

\section{References}

Akbarimoghaddam H, Galavi M, Ghanbari A, Panjehkeh N (2011) salinity effects on seed germination and seedling growth of bread wheat cultivars. Trakia J Sci. 9:43-50.

Allen SG, Dobrenz AK, Schonhorst MH, Stone JE (1985) Heritability of $\mathrm{NaCl}$ tolerance of alfalfa during seed germination. Agron J. 77: 99-101.

Amini F, Mirlohi AF, Majidi MM, Shojaiefar S, Kolliker R (2010) Improved polycross breeding of tall fescue through marker-based parental selection. Plant Breed. 130:701-707.

Amini F, Majidi MM, Mirlohi AF (2013) Genotype-environment interaction for seed yield and certain agronomical traits in half sib families of tall fescue (Festuca arundinacea Schreb.). Crop Sci. 53:411-421.

Amini F, Mirlohi AF, Majidi MM (2016) The Possibility use of AFLP molecular markers and phenotypic traits to increase forage yield in tall fescue (Festuca arundinacea Schreb.). J of Agric Sci Tech. 18: 1419-1429.

Ashraf M, Bokhari H and Cristiti S N (1992) Variation in osmotic adjustment of lentil (Lens culimaris Medic) in response to drought. Acta Bot Neerl. 41: 51-62.

Ashraf M, McNeily T, Bradshaw AD (1987) selection and heritability of tolerance to sodium chloride in four forage species. Crop Sci. 227:232-234.

Barker RE, Kalton KK (1989) Cool season forage grass breeding: progress, potentials, and benefits p 5-20. In: Sleper DA, Assay KH, Pedersen JF. (eds) Contribution from breeding forage and turf grasses, Crop Science Society of America. CSSA Special Publication Madison.

Bohm W (1979) Methods of Studying Root Systems, SpringerVerlag, Berlin.

Carpici EB, Celik N, Bayram G (2009) Effects of salt stress on germination of some maize (Zea mays L.) cultivars. Afr. J. Biotechnol 8:4918-4922.

Dai J, Huff DR, Schlossberg MJ (2009) Salinity effects on seed germination and vegetative growth of green-type Роа аппиа relative to other cool-season turf grass species. Crop Sci. 49:696-703.

DeRose-Wilson L, Gaut BS (2011) Mapping salinity tolerance during Arabidopsis thaliana germination and seedling growth. Plos One 43(5):476-81.

Dhillon NPS (1995) Seed priming of male sterile muskmelon (Cucumis melo L.) for low temperature germination. Seed Sci Technol. 23: 881-884.

Falconer DS, Mackay TFC (1996) An Introduction to Quantitative Genetics, Ed. 4. Prentice Hall, London.

Gomez KA, Gomez AA (1984) Statistical procedures for agricultural research 3 edn. John wiley and sons, NewYork.

Gregorio GB, Senadhira D (1993) Genetic analysis of salinity tolerance in rice (Oryza sativa L.) Theor Appl Genet. 86: 333338.

Horst GL, Beadle NB (1984) Salinity affects germination and growth of tall fescue cultivars. J Am Soc Hortic Sci. 109:419422 .

Horst GL, Dunning NB (1989) Germination and seedling growth of perennial ryegrass in soluable salts. J Am Soc Hortic Sci. 114:338-342.

Horst GL, Taylor RM (1983) Germination and initial growth of Kentucky bluegrass in soluble salts. Agron J. 75:679-681.

Hussein MM, Balbaa LK, Gaballah MS (2007) Salicylic acid and salinity effects on growth of maize plants. Res J Agric Biol Sci. 3(4): 321-328.
Jones HG (2007) Monitoring plant and soil water status: established and novel methods revisited and their relevance to studies of drought tolerance. J Exp Bot. 58:119-131

Khodarahmpour Z, Ifar M, Motamedi M (2012) Effects of $\mathrm{NaCl}$ salinity on maize ( Zea mays L.) at germination and early seedling stage. Afr. J. Biotechnol. 11:298-304.

Kölliker R, Boller B, Widmer F (2005) Marker assisted polycross breeding to increase diversity and yield in perennial ryegrass (Lolium perenne L.). Euphytica 146: 55-65

Mantri N, Patade V, Penna S, Ford R, Pang E (2012) Abiotic stress responses in plants: present and future. In: Ahmad P, Prasad MNV (eds) Abiotic stress responses in plants: metabolism, productivity and sustainability. Springer, New York.

Marcum K (1994) Salt tolerance mechanisms of turf grasses. Coif Course Management, 55-59.

Misra N, DwivediUN (2012) Genotypic differences in salinity tolerance of green gram cultivars plant. Intl J Farm Alli Sci. 166:1135-1142.

Munns R, James RA, Läuchli A (2006) Approaches to increasing salt tolerance of wheat and other cereals. J Exp Bot. 57: 10251043.

Munns R, Tester M (2008) Mechanisms of salt tolerance. Annu Rev Plant Biol. 59: 651-681.

Pezzani F, Montana C (2006) Inter-and intra-specific variation in the germination response to light quality and scarification in grasses growing in two-phase mosaics of the chihuahuan desert. Ann Bot. 97: 1063-1071.

Rehman S, Harris PJC, Bourne WF, Wilkin J (1996) The effects of sodium chloride on germinating and the potassium and calcium contents of Acacia seeds. Seed Sci Technol. 25: 45-57.

Rouhi H, Abutalebian MA, Sharifzadeh F (2011) Seed Priming Improves the Germination Traits of Tall Fescue (Festuca arundinacea). Not Sci Biol 3(2): 57-63.

Safarnejad A, Collin H, Bruce KD, McNeilly T (1996) Characterization of alfalfa following in vitro selection for salt tolerance. Euphytica 92: 55-61.

Shalhevet J (1993) Plant under salt and water stress. In: Plant adaptation to environmental stress (eds: L. Fowden, T. Mansfield and J. Stoddard). Chapman and Hall.

Shanker AK, Venkateswarlu B (2011) Abiotic stress in plants mechanisms and adaptations. InTech, Rijeka.

Tari I, Kiss G, Deer AKC, Siszar J, Rdei L, Galle ÁG, Émes KH, Orvath F, Poor PS, Zepesi Á, Simon LM (2010) Salicylic acid increased aldose reductase activity and sorbitol accumulation in tomato plants under salt stress. Biol Plantrum. 54: 677-683.

Wang S, Zhang Q (2010) Responses of creeping bentgrass to salt stress during in vitro germination. Hort Sci. 45:1747-1750.

Xu S, Hu B, He Z, Ma F, Feng J, Shen W, Yan J (2011) Enhancement of salinity tolerance during rice seed germination by presoaking with hemoglobin. Int J Mol Sci. 12:2488-2501.

Xu WW, Sleper DA (1994) Phylogeny of tall fescue and related species using RFLPs. Theo Appl Genet. 88:685-690.

Yensen NP (1995) In: Khan MA, Ungar LA (Eds.), Biology of salt tolerance plants. University of Karachi Pakistan.

Zabihi-e-Mahmoodabad R, Jamaati-e-Somarin S, Khayatnezhad M, Gholamin R (2011) The study of effect salinity stress on germination and seedling growth in five different genotypes of wheat. Adv Environ Biol. 5(1):177-179.

Zhang Q, Rue K, Wang S (2012) Salinity effect on seed germination and growth of two warm-season native grass species. Hort Sci. 47:527-530.

Zhou H (2006) Effect of different treatment on four tall fescue varieties seed germination. Southwest Hort. 2: 25-26. 